\title{
Construction of China's Foreign Talent Governance System under the Context of New Era
}

\author{
Hanwen Zhang \\ Faculty of Education, Office of International Cooperation and Exchange \\ Northeast Normal University \\ Changchun 130024, China
}

\begin{abstract}
As the process of internationalization deepens, foreign talents have become the target of fierce competition among countries all over the world. Similarly, China also has launched a series of policies with the intention to occupy talent highland and achieve the strategy of strengthening the country through talents. However, currently, it seems that some departure appears between aspirational policy formulation and practical implementation. To bridge the gap, this paper took Chinese national policy discourse as the data recourse and conducted in-depth analysis on its effectiveness, equilibrium, operability and synergy. Through literature review and international comparison, this paper argues that the government should transform its original role and the overall policy design needs to be optimized. In addition, properly handling the relationship among all stakeholders is also essential to the construction of a sound foreign talent governance system.
\end{abstract}

Keywords—construction; foreign talent; governance; new era

\section{INTRODUCTION}

"Opinions on deepening the reform of personnel development system and mechanism" was issued by Central Committee of the Communist Party of China in March 2016. This opinion launches a new discourse on the importance of the transition from management to governance. Meanwhile, with the acceleration of economic globalization and talent internationalization, the scope of talent work gradually extends to involve those in foreign countries. Therefore, strengthening the construction of foreign talent governance system is becoming inevitable in response to the challenges of the time. Under the background of new era in China, this not only helps enrich the theoretical system of socialist talent governance with Chinese characteristics but also has great implications for its economic transformation and social progress.

\section{CONCEPTUAL AND THEORETICAL FRAMEWORK}

\section{A. Connotation and Challenges of New Era}

On October 18, 2017, Chinese General Secretary Xi Jinping delivered a speech at the 19th National Congress and declared that after decades of hard work, socialism construction with Chinese characteristics has crossed the threshold into a new era. From a historical perspective, China's social development has experienced three stages. New China starts from the founding of the country in 1949 and at that time China chose to develop through a socialist road. After 1978, when the Third Plenary Session of the 11th Central Committee was held, China determined to construct socialism with Chinese characteristics and this period is called new stage. After the 19th National Congress in 2017, China further clarifies its goal of building a moderately prosperous society in all aspects, marking the arrival of new era.

Under the context of new era, the principal contradiction of Chinese society has evolved into the tension between people's ever-growing needs for a better life and current unbalanced as well as inadequate development. It is revealing to see that in addition to demands for consumption, people are attaching more importance to fairness and justice.

\section{B. Theoretical Foundation of Governance System Construction}

As a concept, governance incorporates with the very long history of governing, rule, authority structures, and domination. [1] According to the Cambridge Business English Dictionary, "governance" implies the way that organizations or countries are managed at the highest level and the systems for doing this. [2] In terms of the emergence of governance theory, it is initially a theoretical and practical response from governments to ongoing changes at economic, political, and ideological fields. The concern is mainly focused on what kind of management should be adopted to maximize public interests. In summary, governance has four distinct characteristics. First, it is a process, instead of a set of rules or regulations, nor an activity. Second, the establishment of governance depends on reconciliation, rather than domination. Third, governance is connected with diverse subjects, including both public and private sectors. Finally, governance itself also varies in accordance with continuous interaction.

\section{The relationship among New Era, Foreign Talents and Governance}

Against the backdrop of the knowledge economy, talent resources become the first resources, and the role of foreign talents begins to stand out as the driving rationale for social development. Correspondingly, in recent years, the Chinese government has launched a series of active policies to attract high-level talents from all over the world. However, the mobility of these foreign talents is highly frequent. This not only seriously violates the original intention of policy formulation but also does great damage to the sustainable development of related work. At the same time, people's desire for fairness and justice increases dramatically during this period, and they are eager to participate more in social public affairs. Therefore, on the basis of governance theory, 
the construction of an efficient foreign talent system becomes a matter of particular urgency.

\section{OVERVIEW OF FOREIGN TALENT MANAGEMENT IN CHINA}

Foreign talent work is a complex system related to foreign affairs, public security, education, commerce, technology and so on. Among all the involved departments, National Foreign Experts Bureau functions as the centralized management one. Viewing through the lens of management manner, China is still accustomed to adopting a top-down policy output to regulate foreign talents' introduction as well as development. Therefore, this paper takes national policy discourse as the data resource and strives to deeply explore existing problems within this process. Then viable recommendations are provided for future action.

\section{A. Evaluate Policy Effectiveness Based on Legal Effect.}

The whole situation of foreign talents can be reflected through laws, international conventions, administrative regulations and general policy documents. At present, at the legal level, China's Constitution, Entry and Exit Administration Law and Nationality Law all have relevant contents with regard to foreign talents. As the country's fundamental law, the Constitution enjoys the highest legal effect, among which Article 32 stipulates that "China protects the legitimate rights as well as interests of foreigners in China, and they must abide by the laws of China." However, this only appears in the general provision and there are no supporting documents for operation. Given the overall composition (see Fig.1), general policy documents account for $78 \%$ of the total and only $6 \%$ fall into the scope of the law. Obviously, the absence of guidance from the basic law will result in conflict or convergence among policies. This may also greatly hamper the policy process moving towards systematization, structuration, standardization and scientification. [3]

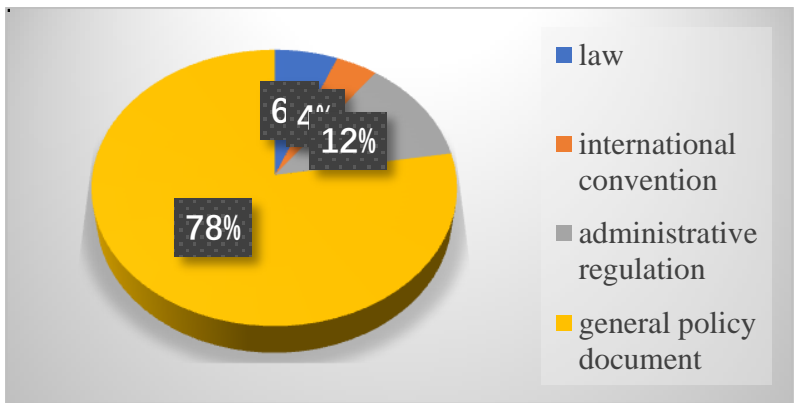

Fig.1. Policy distribution on the basis of the legal effect

\section{B. Evaluate Policy Equilibrium Based on Identified Category}

National Foreign Experts Bureau issued "Announcement on Clean-up Results of Regulatory Documents Covered by the Reform of Streamlining Administration, Strengthening Regulation and Improving Service" in December 2017. Among the 53 documents that continue to be valid, 15 documents concentrate on overseas training and 38 documents take foreign talents as the focus. As far as concrete content is concerned, these 38 documents cover 6 aspects in all, namely comprehensive management, visa affairs, welfare benefits, scientific research, abolition notice and project management (see Fig.2). It can be concluded that the majority of existing policies are normative. By way of contrast, welfare policies and development policies are far from sufficient. As a matter of fact, the intellectual resources introduced must be preserved, that is, to avoid loss; and meanwhile be value-added, that is, to create opportunities for training and development. [4] In this sense, the proportion of current policy categories needs to be further optimized.

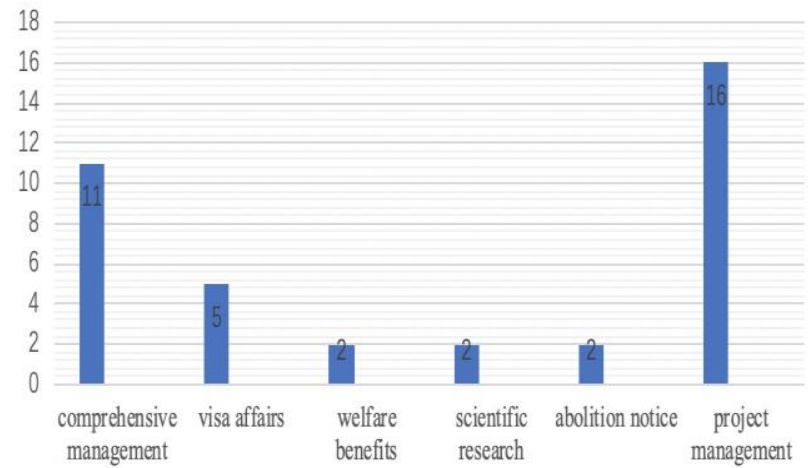

Fig.2. Subject distribution of 63 valid documents

\section{Evaluate Policy Operability Based on Respective Content}

At present, the guiding policy documents in China are seriously mismatched with the operational documents, resulting in an imbalance in the policy system. Questions such as what are the specific rights and interests of foreign talents, what are the responsibility boundaries and cooperation areas for governmental functional units need further clarification. Take "Interim Measures for Participation in Social Insurance of Foreigners in China" as an example. The document was issued by Ministry of Human Resources and Social Security in 2011 and it clearly stipulated that foreigners should participate in basic endowment insurance, medical insurance, work injury insurance, unemployment insurance and maternity insurance according to law. Both the domestic working units and foreigners shall pay corresponding social insurance premiums. However, there is no practical guidance on this initiative. As a consequence, the working units have no ideas about how to pay the premium for foreign talents. In some provinces, even the working staff at social insurance departments are also at a loss when confronted with this issue. What's worse, the document does not explain the results of failure to perform required obligations. Therefore, this policy has not been fully implemented in many cases.

\section{Evaluate Policy Synergy Based on Issuing Subjects}

As mentioned above, foreign talent work is closely connected with multiple departments. Only when the chain with clear division and efficient cooperation forms will talent work achieve "no absence" and "no duplication". Through the analysis of the amount of policy issuing subjects (see Fig.3), $82 \%$ are issued solely by the Foreign Experts Bureau and documents jointly issued by 3 or more departments account for only $12 \%$. This figure has shown without a shadow of a doubt that coordination among different departments still needs more reflection and improvement. Furthermore, the lack of tracking feedback mechanism and dynamic adjustment mechanism also breaks the connection between policy intention and actual working effects. 


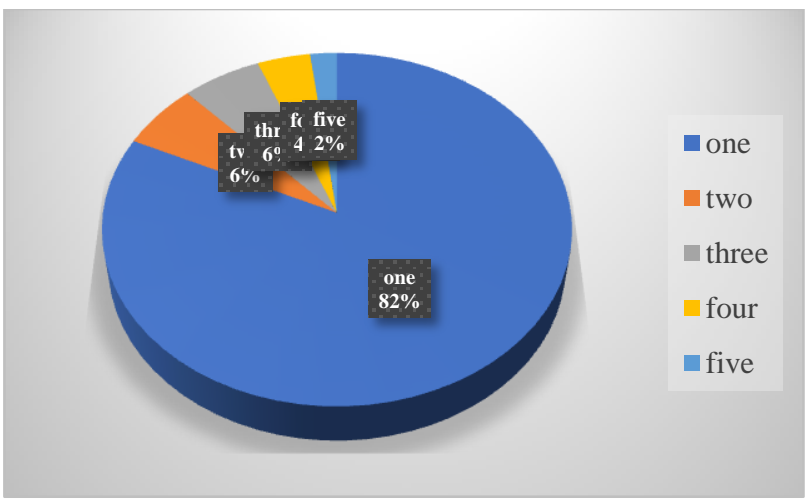

Fig.3. Policy distribution on the basis of the amount of issuing subjects

\section{STRATEGIES FOR CONSTRUCTING CHINA's FOREIGN TALENT GOVERNANCE SYSTEM}

\section{A. Transformation of the Government's Role is the Basic Premise}

The growth and development of foreign talents require catalysis and stimulation from the external environment. To enhance the working efficiency of intelligence introduction, it is of great necessity for the Chinese government to actively change the original ideas and fully respect the rules of the market economy as well as talent growth. The policy of "streamlining administration, strengthening regulations and improving services" is a beneficial attempt in this respect. And the government should speed up the internal reform process and push forward this policy in all directions.

Specifically speaking, for instance, on the issue of foreign talent introduction, the main role of the government is not to carry out detailed work through administrative means, nor to provide preferential treatment to some minorities through temporary measures. On the contrary, it should rely on the market mechanism to promote the talent economy. That means, the government should heighten its awareness to create a fair and inclusive environment for the employment and the entrepreneurship of foreign talents. [5]

\section{B. Improvement of the Policy's Overall Design Functions as the Core}

\section{1) Strengthening Legal Provision Pertaining to Foreign}

\section{Talents}

Safeguarding the legitimate rights and interests of foreign talents is the solid foundation for the realization of the connotative development within talent work. High-level foreign talents pay more attention to their own rights and interests, especially those from developed countries. They want to apply laws to protect their rights in the working countries, such as personal right, property right and so on. [6] On the basis of precisely understanding the mentality of these foreign talents, the Chinese government should increase relevant legal supply to meet these reasonable requirements. The provision of such basic law can act as a substantial cornerstone for rights protection. Meanwhile, the guidelines for other underpinning policies should be offered as well.

In addition, some attention might be drawn to the field of immigration law and nationality law. Valuable experiences can be obtained from history. During the sluggish recovery of the world economy, in order to seek technological breakthroughs and promote the country's high-end manufacturing industry, the United States launched "Advanced Manufacturing Partnership Program", "National Strategic Plan for Advanced Manufacturing", and implemented "Re-Industrialization Strategy". Through adjustment of the immigration law and establishment of the temporary labor planning system, more than 14 million temporary technical workers entered the United States between 2001 and 2012. [7] This has exerted a profound effect on its future growth. Combing with the current situation, the Chinese government can consider the revision of the immigration law as well as the nationality law under appropriate circumstances, and actively creates all favorable conditions with the aim of encouraging various talents to participate in the construction of the country.

2) Optimizing Policy Structure to Enhance Work Passion

In order to win the competitive initiative and transform talent advantage into development advantage, it is instrumental to release the constraints of institutional mechanisms and add more supportive policies. There is a relatively fixed cycle in the cultivation, generation and development of talents. Each stage needs the guarantee from policies. In compliance with three main links involved, namely introduction, retention, and application, policies towards foreign talents can be classified into three categories: incentive policies, guarantee policies and development policies. [8]

Incentive policies refer to policies that attract talents through material rewards and honors. For foreign talents with outstanding performance, related policies can be made to provide financial support and give them some one-time bonus; or award honorary titles such as honorary professors. Guarantee policies aim to facilitate the work and life of foreign talents in the new environment. Detailed policies should be developed in the field of housing, medical care, education, social security and so on. It is also suggested to make efforts towards undifferentiated social welfares for foreign talents who are interested in staying in China for a long time. Developmental policies are a series of preferential policies formulated for talents' further innovation. Establishing political support for foreign talents' career trajectory is also one of the effective means to strengthen the cohesion between.

3) Specifying Policy Content to Improve Implementation Effects

Only by reliance on the support of operational documents can guidance documents truly make a difference. Intellectual property rights protection in the United States is a good example to follow. From the national level, Article 8 of the first chapter of its Constitution, which was enacted in 1789, states that Congress has the power to "ensure the exclusive rights of authors and inventors to their respective works and inventions within a certain period of time to promote scientific development. Since then, the United States has successively enacted the "Patent Law", "Trademark Law", "Copyright Law", "Internet Law" and "Software Patent Law" for comprehensively promoting the protection of intellectual property rights in all respects. As far as universities and research institutions are concerned, they also have concrete documents to carry out the policy to a full extent. For instance, 
at the intellectual property chapter of Princeton Faculty Rules and Procedures, it clearly states that the Dean for Research is responsible for the implementation of the copyright policy under the general oversight of the University Research Board. The Office of Technology Licensing is responsible for the providing management of copyrights and licensing services for the university community. [9]

Taking advantage of these beneficial experiences, a lot of work can be done to push forward policy implementation. Careful consideration should be taken and detailed guidelines should be given as to the process of foreign talents' requirement identification, welfare offering, supervision and assessment.

\section{4) Establishing a Complete Network to Promote Full} Coverage of Foreign Talent Work

The dilemma of talent work emanates from the lack of collaborative governance to some extent. To break this dilemma, adopting a multi-center, multi-method network governance model is extremely important. From the horizontal perspective, related governmental functional units, such as the Ministry of Human Resources and Social Security, Ministry of Finance, Development and Reform Commission should set up a coordination mechanism for information sharing. In addition to clarifying the boundaries of responsibilities, they should meet regularly to discuss problems which need to be resolved. Thus, the phenomenon of functional vacancy can be avoided. From the vertical perspective, properly handling the relationship between central policies and local policies is also crucial. Though National Foreign Experts Bureau is the centralized management department, it cannot exercise all functions by itself. In this case, it can still in charge of foreign talents' overall qualification certification, registration, and reputation evaluation. Other items, such as motivation can be detached to different employment agencies at all levels.

5) Realizing the Potential of All Stakeholders is the Top Priority

Actively keeping the harmonious relationship among different subjects is high on the strategic agenda. All stakeholders are inseparable from the introduction and development of foreign talents. These stakeholders themselves are also intertwined with one another. The allocation of human resources needs to be determined jointly by the government's policy inclination, employers' decisions under the market's supply and demand mechanism, industry's actual demand in accordance with development, and also individual's degree of devotion to talent capital. Effective docking of information between the government's precise policy supply and the employers' actual talent demand is also a key component of the foreign talent governance system. In summary, it is a complicated system affected by multiple factors.

More concretely, under this "common governance" paradigm, the government is in charge of providing resources such as policies, systems, laws as well as regulations, financial funds and tax reductions or exemptions through institutional arrangements. Society assumes the responsibility of supplying foreign talents with auxiliary resources. The market can help with releasing useful information on industrial demands, industry platforms, some intermediary services and so on. In terms of employers, they play the role of giving access to competitive compensation and suitable working environment. In the end, the resources invested by the government, the market, the society, and the employers collectively constitute a resource pool that accumulates diversified resource elements. [10] All these stakeholders work together to contribute to the flourishing of foreign talent work.

\section{CONCLUSION}

The construction of China's foreign talent management system under the new era is not accomplished by one's own efforts. It is a complex system that requires the joint efforts of all parties. Conducting policy design in a holistic manner and strategically handling the relationship among different subjects will definitely speed up the achievement progress.

\section{ACKNOWLEDGMENT}

This paper is supported by Youth Fund Project for Philosophy and Social Science of Northeast Normal University (Funded by Special Fund for Basic Scientific Research in Central Universities) - Research on Talent Introduction Mechanism at Universities under "Belt and Road" Initiative (Project Number: 1709233), Key Project of the 13th Five-year Project for Education Science in Jilin Province (General Planning) - Research on Difficulties and Solutions of Talent Introduction at Universities in Jilin Province under "Double First-class" Initiative (Project Number: ZD18005), and "Double First-Class" Construction and Higher Education Internationalization Project of China Association of Higher Education - Research on Foreign Talents' Rights Protection under "Double First-Class" Initiative (Project Number: 2019SYLZD08).

\section{REFERENCES}

[1] Tiihonen Seppo. From Governing to Governance [M]. Tampere University Press, 2004

[2] Cambridge Business English Dictionary [M]. Cambridge University Press, 2011(11)

[3] Dailiang Zheng, Shuhua Zhong. Status Quo, Problems and Countermeasures of China's High-level Talent Policy[J] technological management, 2012(9) (In Chinese)

[4] Xiyuan Li, Junwei Chen. Effectiveness Evaluation of Talent Policies at National High-tech Zones-Taking Wuhan Optics Valley, Beijing Zhongguancun Technology Park and Suzhou Work Park as Examples[J]. Technology and Industry, 2014(7) (In Chinese)

[5] Rui Sun. Constructing a Talent Governance System with Chinese Characteristics-Learning the Spirit of the Important Speech of General Secretary Xi Jinping's Talent Work Series [J]. Administrative Management Reform, 2015(4) (In Chinese)

[6] Jing Gu. Analysis on the Legal System of Protecting the Rights and Interests of Foreign Experts [D]. East China University of Political Science and Law, 2014 (In Chinese)

[7] Maoxin Liang. Why Talents Prefer to Go to the United States [J]. Journal of Social Sciences, 2014(8) (In Chinese)

[8] Shuai Wu. Policy Combing and Classification Comparison of Introduction of Overseas High-level Talents in China $[\mathrm{J}]$. First Resources, 2013(9) (In Chinese)

[9] Office of the Dean of Princeton University. Rules and Procedures [EB/OL]. [2019-08-12] https://dof.princeton.edu/sites/dof/files/images/Princeton $\% 20$ Faculty\% 20Rules\%20and\%20Procedures.pdf? 
[10] Zhongyan Liu. Connotation, Predicament and Strategy for Talent Governance in China: Based on Innovation-driven Development
Analysis [J]. Human Resource Development of China, 2016(17) (In Chinese) 